of absorption. This estimate is undoubtedly low because the blood draining the posterior part of the rumen carried a lower concentration of volatile acid than that draining the anterior part of the rumen and for this no allowance was made in the calculation.

It is not yet possible to account for the fermentation of carbohydrate in the rumen on a quantitative basis. We have shown that the quantity of volatile acids is large enough to make them of interest when the nutrition of the animal is considered as a whole. In addition we have shown not only that the quantity present is large but also that these acids are being absorbed continuously from the organs in which they are produced.

In order to assess the value of any product of bacterial digestion in the rumen it is necessary to know at what rate and in what quantity the nutrient in question becomes available to the animal. There are 2 ways for this; the first we have shown is by direst absorption, the second is by passage to the abomasum and absorption from the small intestine. Until the quantities of material passing by this latter route, from the stomach to the intestine, can be measured quantitatively no sure statement can be made as to the significance of the various nutrients which are produced in the rumen as a result of bacterial activity.

\title{
REFERENCES
}

Elsden, S. R. (1945). Biochem. J. 39, in the press.

Hale, E. B., Duncan, C. W. and Huffman, C. F. (1940). J. Dairy Sci. 23, 953.

MeAnally, R. A. (1942). Biochem. J. 36, 392.

Trautmann, A. (1933). Arch. Tierernähr. Tierz. 9, 178.

Washburn, L. E. and Brodie, S. (1937). Res. Bull. Mo. agric. Exp. Sla. no. 263.

\section{Volatile Fatty Acids in the Rumen of the Sheep}

\author{
Dr. S. R. Elsden (Agricultural Research Council Unit of Animal \\ Physiology, Department of Biochemistry, Cambridge)
}

Dr. Phillipson has drawn attention to the fact that there is a high concentration of volatile fatty acids in the rumen and that these are absorbed into the blood stream (Marshall and Phillipson, 1945). Sir Joseph Barcroft will discuss the fate of these compounds once they are absorbed (Barcroft, 1945). It is my purpose to describe some of the steps in the formation of these compounds, and the type of organism responsible for their formation.

Phillipson and McAnally (1942) showed that when various pure carbohydrates were introduced into the rumen of sheep, through a fistula, the carbohydrates disappeared and there was an increase in the concentration of volatile fatty acids, the rate of formation of which was dependent on the nature of the carbohydrate. Thus, glucose, fructose and sucrose were fermented very rapidly, and disappeared within 3 to 4 hours. Starch was fermented more slowly, and cellulose more slowly still. In addition, when glucose, fructose or sucrose was fermented, lactic acid was formed in quantity, only to be converted into volatile fatty acids.

\section{Production of Volatile Fatty Acids by Fermentation in Vivo}

The starting point of the work I am about to describe was a more detailed examination of the process of the fermentation of glucose by the voL. 3,1945 ] 
rumen micro-organisms and, to this end, experiments were made both in vivo and in vitro. For the experiments in vivo, Hampshire Down sheep were employed, provided with a permanent rumen fistula. At the beginning of the experiments the animals were on a diet of poor quality hay and were not thriving. They were fed once a day, in the morning. On the day before an experiment the animal was fed as usual and, after the meal, the cage was swept and only water provided. On the day of the experiment at about 9.0 a.m., a sample of rumen contents was obtained for analysis and, an hour later, a second sample was withdrawn; immediately after this $100 \mathrm{~g}$. glucose dissolved in $400 \mathrm{ml}$. water at $38^{\circ} \mathrm{C}$. was given. Further samples of rumen contents were withdrawn at intervals over the next 24 hours. While the diet was one of poor quality hay, glucose was fermented very slowly and remained in the rumen for as long as 16 hours; scarcely any lactic acid was formed, and there was only a very slight increase in the concentration of volatile fatty acids. Experiments such as this were repeated over a period of 2 months with the same result. At the end of 2 months the animals were in such poor condition that the diet was changed to one of clover hay.

Fourteen days after the change in diet, the glucose test was repeated again. It was observed that glucose was now fermented much more rapidly, and disappeared from the rumen within 9 hours. A considerable amount of lactic acid was produced, and there was a marked increase in the concentration of volatile fatty acids. In short, a response was obtained much more in keeping with those recorded by Phillipson and McAnally (1942).

Microscopic examination revealed that a profound change had taken place in the bacteria present in the rumen. As long as glucose persisted in the rumen large numbers of diplococci and streptococci could be seen; these stained a deep blue with iodine, so much so that when iodine was added to the rumen liquor the mixture turned a dark purple colour. Before the addition of glucose to the rumen, the micro-organisms did not react to iodine, but 30 minutes after dosing the reaction had reached what appeared to be its maximum intensity. The iodine reaction began to disappear when all the glucose had been removed from the rumen, and had vanished completely within 18 hours after dosing. The organisms, though still present in large numbers, had lost their store of material staining like starch.

The glucose test was repeated again about 40 days from the changing of the diet. Glucose was fermented even more rapidly than before, and disappeared from the rumen within $3 \frac{1}{2}$ hours after dosing. There was a correspondingly rapid formation of lactic acid which, in its turn, quickly gave place to volatile fatty acids. A detailed study was made of the changes in the individual volatile fatty acids during the course of the experiment, and it was found that the ratio of acetic to propionic acid decreased during the fermentation, indicating that more propionic than acetic acid was produced. Table 1 illustrates this point which will be referred to again later.

Microscopic examination of the flora at this stage revealed that a further change had taken place. There were now very few iodophile cocci to be seen but a new type of organism had appeared which closely resembled 
a yeast, stained a deep brown with iodine as long as glucose persisted in the rumen, and multiplied by binary fission.

\section{TABLE 1}

Volatile Fatty Acids Produced in the Rumen of the Sheep after the Administration of $100 \mathrm{~g}$. Glucose in $400 \mathrm{ml}$. Water

\begin{tabular}{|c|c|c|c|c|c|}
\hline \multirow{3}{*}{$\begin{array}{l}\text { Time } \\
\text { hours }\end{array}$} & \multicolumn{5}{|c|}{ Volatile acid produced } \\
\hline & \multicolumn{4}{|c|}{ Millimols per $100 \mathrm{ml}$. rumen liquor } & \multirow{2}{*}{$\begin{array}{l}\text { Ratio } \\
\text { acetic: } \\
\text { propionic }\end{array}$} \\
\hline & Total & Butyric & Propionic & Acetic & \\
\hline $0^{*}$ & $2 \cdot 94$ & 0.46 & 0.47 & $2 \cdot 01$ & $4 \cdot 28$ \\
\hline $1 \cdot 0$ & $4 \cdot 30$ & 0.61 & $I \cdot 01$ & 2.68 & $2 \cdot 66$ \\
\hline $3 \cdot 30$ & 4.90 & 0.77 & 1.79 & $2 \cdot 34$ & $1 \cdot 30$ \\
\hline $6 \cdot 10$ & $3 \cdot 81$ & 0.58 & $1 \cdot 32$ & 1.91 & $1 \cdot 45$ \\
\hline $12 \cdot 40$ & $2 \cdot 97$ & 0.27 & 0.85 & 1.85 & $2 \cdot 18$ \\
\hline $17 \cdot 40$ & $2 \cdot 06$ & 0.21 & 0.58 & $1 \cdot 27$ & $2 \cdot 19$ \\
\hline $24 \cdot 0$ & $1 \cdot 26$ & $0 \cdot 21$ & $0 \cdot 25$ & 0.80 & $3 \cdot 20$ \\
\hline
\end{tabular}

* Glucose given immediately afterwards.

\section{Production of Volatile Fatty Acids by Fermentation in Vitro}

Within a few days of this experiment a fermentation of glucose was carried out in vitro with rumen liquor from this same sheep for the inoculum. The medium was buffered with bicarbonate under a gas phase of $\mathrm{CO}_{2}$; the final concentration of bicarbonate approximated to that in the parotid saliva of the sheep and was about $0 \cdot 14 \mathrm{M}$; nitrogen was provided in the form of ammonia, added as ammonium phosphate, and calcium, magnesium and potassium were present in amounts corresponding with those in serum. Fifty ml. of rumen contents were made up to $450 \mathrm{ml}$. with the medium; addition was made of $50 \mathrm{ml} .10$ per cent. glucose, and the whole was made anaerobic under an atmosphere of $\mathrm{CO}_{2}$ and incubated at $38^{\circ} \mathrm{C}$. for 72 hours, samples being withdrawn at suitable intervals for analysis. There was a close similarity between the course of the fermentation in vitro and in vivo; glucose was rapidly fermented in both cases, lactic acid appeared as an intermediary product, and there was more propionic acid formed than acetic. There was a close similarity also in the flora which developed as far as could be judged by microscopic observation; there were very few iodophile cocci but large numbers of yeasts.

The close similarity of the results obtained in vitro to those obtained in vivo justified the further use of experiments in vitro to examine the nature of the volatile fatty acids produced from various substrates. Table 2 records the percentage composition obtained by steam distillation of the volatile fatty acids produced from cellulose, glucose, lactic acid and dried grass, the last being included for comparative purposes. The figures given are averages from fermentations with rumen contents from 8 different sheep. With the exception of grass, propionic acid was the predominating acid in each case.

vox. 3, 1945] 
TABLE 2

Avfirage Percentage Composition of the Mrxture of Volatill: Fatty Acids

Produced by Fermentation in Vitro with Different Substrates and With the Rumen Liquor of 8 Different Individual Sireep

\begin{tabular}{|c|c|c|c|c|}
\hline \multirow{2}{*}{\multicolumn{2}{|c|}{ Substrate }} & \multicolumn{3}{|c|}{ Volatile acid, per cent. } \\
\hline & & $\frac{\text { Acetic }}{43.5}$ & $\frac{\text { Propionic }}{5 \mathrm{l} \cdot 5}$ & $\frac{\text { Butyric }}{5 \cdot 0}$ \\
\hline $\begin{array}{l}\text { Cellulose } \\
\text { Glucose } \\
\text { Lactic acid } \\
\text { Dried grass }\end{array}$ & $\begin{array}{l}\ldots \\
\cdots \\
\ldots\end{array}$ & $\begin{array}{l}43 \cdot 5 \\
28 \cdot 2 \\
33 \cdot 7 \\
64 \cdot 0\end{array}$ & $\begin{array}{l}51 \cdot 5 \\
47 \cdot 0 \\
53 \cdot 5 \\
20 \cdot 0\end{array}$ & $\begin{array}{r}5 \cdot 0 \\
24 \cdot 8 \\
12 \cdot 8 \\
16 \cdot 0\end{array}$ \\
\hline
\end{tabular}

\section{Significance of the Results}

It will be seen that the rumen flora in the sheep can vary enormously, and in fact does so, with the nature of the diet. Similar results have been obtained in South Africa by Quin (1943) and Van der Wath (1942). Quin observed in the flora of the rumen of the sheep a series of changes, similar to those described here, when the diet was changed from veld grass hay to lucerne or lucerne hay. He noted also an increased ability to ferment glucose, as judged by the rate of gas production from the rumen, when the diet was thus changed. He associated fermentation of the most rapid type with a rumen flora rich in the yeast like form which he has named Schizosaccharomyces ovis. The organism has not as yet been isolated in pure culture, but Quin observed that suspensions of the organism could be obtained by fractionation with the centrifuge, and that such suspensions fermented glucose very rapidly. From my own preliminary experiments it appears that these organisms produce no alcohol, but confirmation of this point awaits isolation of the organism and its study in pure culture.

According to Van der Wath (1942) the iodophile coceus is a dominant member of the flora when the animals are fed on a diet rich in starch. $\mathrm{He}$ isolated the organism in pure culture and showed that it will ferment glucose and starch rapidly with the production of acid. As the organism is a coccus it is not unlikely that the acid produced will prove to be lactic acid.

The formation of considerable quantities of propionic acid during the fermentation of glucose in vivo and glucose, lactic acid and cellulose in vitro was surprising. The fact that propionic acid was produced anaerobically from lactic acid provided the clue to its origin. Such a fermentation is highly characteristic of the genus Propionibacterium, a group of organisms well known to the dairy bacteriologists. Members of this genus have been isolated from the rumen of all sheep examined, and also from that of an ox. This evidence makes it certain that organisms of this group are functioning members of the rumen flora, and that they are responsible for producing the propionic acid and part of the acetic acid invariably found in the rumen. It is interesting to recall that the early workers on this group of organisms, seeking to explain their occurrence in certain forms of dairy produce, found that large numbers were present in the faeces of cows (Burri, 1911), and in both the abomasum and crude rennet made from the abomasum of calves (Thöni, 1906). 
There is a further point to be made as to the origin of the large amounts of acetic acid which make it the predominating acid in the rumen (Marshall and Phillipson, 1945), and I must state at once that I do not know how it is formed. It is probable to my mind that it arises from the polysaccharides other than cellulose in feeding stuffs and, in particular, from the so called hemicelluloses and pentosans, about which we know little or nothing. Until, however, a detailed study of these substances has been made, and until they are available in a state of purity and in large quantities, the mode of production of volatile fatty acids from them in the rumen is a matter of speculation.

\section{Summary}

1. The diet of the ruminant conditions the type of flora in the rumen. This may be of practical importance because it is well known that a sudden change of diet is not to the animal's advantage.

2. Three types of organism have now been associated with the fermentation of carbohydrate in the rumen: a yeast like form which becomes dominant when the animal consumes a diet rich in readily fermentable carbohydrate; a coccus isolated in pure culture by Van der Wath (1942) which, while fermenting glucose or starch stores a polysaccharide which stains blue with iodine; members of the genus, Propionibacterium, which have been shown to be responsible for the production of the propionic acid and part of the acetic acid found in the rumen.

\section{RETERENCES}

Barcroft, J. (1945). Proc. Nutr. Soc. 3, 247.

Burri, R. (1911). TätigkBer. schweiz. milchw. Anst. Bern-Liebefeld, 467.

Marshall, R. A. and Phillipson, A. T. (1945). Proc. Nutr. Soc. 3, 238.

Phillipson, A. T. and McAnally, R. A. (1942). J. exp. Biol. 19, 91.

Quin, J. I. (1943). Onderstepoort J. vet. Sci. 18, 91.

Thöni, J. (1906). Landw. Jb. Schweiz, I.

Van der Wath, J. G. (1942). Thesis. University of Pretoria.

\section{The Utilization of Volatile Acids}

Sir Joseph Barcroft (Agricultural Research Council Unit of Animal Physiology, Department of Physiology, Cambridge)

Dr. Phillipson has told of researches which were initiated by him and which cast quite a new light on the possibilities of ruminant digestion, the gist of which was that the carbohydrate of the diet was largely converted into volatile fatty acids and was absorbed as such (Marshall and Phillipson, 1945) and, in this connection, Dr. Elsden has discussed the chemistry of the digestion of cellulose and other carbohydrates by the flora of the rumen (Elsden, 1945). My part is to take the matter up where they have left it off and to give you the information now available about the fate of the volatile acids actually absorbed.

The first question was to estimate the actual amount of acids which found their way from the gut into the blood. Here let me emphasize the fact that, though our introduction to the subject came from the study of the ruminant, production of volatile fatty acids in the alimentary voI. 3,1945 ] 